ATLANTA

\title{
Abstract: A Product Design and Manufacturing Program
}

Dr. Christopher P. Pung, Grand Valley State University 


\section{A Product Design and Manufacturing Program}

Grand Valley State University's Padnos College of Engineering and Computing changed its traditional Manufacturing Engineering Program to a Product Design and Manufacturing Program. This change is in keeping with the industrial norms of including product and manufacturing engineers in product development teams. This poster will highlight the benefits of the changes. These include an addition of two classes focused on the product design process. The first class is an Introduction to Product Design it uses a semester long project to guide the students through the product development process. It begins with an idea for a product and proceeds through market analysis, specifications, design and a final prototype. The second class is Advanced Product Design it uses a similar project centered class generally starting at the prototype stage and continuing towards a ready for mass production design. This poster will show examples of the projects and methodologies used in these two classes. 